Retraction

\title{
Retraction: Lin, G.-W., et al. Reconstructing the Dynamic Processes of the Taimali Landslide in Taiwan Using the Waveform Inversion Method. Appl. Sci. 2020, 10, 5872
}

\author{
Guan-Wei Lin ${ }^{1, *} *$ and Ching Hung ${ }^{2}[$ \\ Department of Earth Sciences, National Cheng Kung University, No. 1, University Road, Tainan 701, Taiwan \\ 2 Department of Civil Engineering, National Cheng Kung University, No. 1, University Road, \\ Tainan 701, Taiwan; ChingHung@gs.ncku.edu.tw \\ * Correspondence: gwlin@mail.ncku.edu.tw
}

check for

updates

Citation: Lin, G.-W.; Hung, C.

Retraction: Lin, G.-W., et al.

Reconstructing the Dynamic

Processes of the Taimali Landslide

in Taiwan Using the Waveform

Inversion Method. Appl. Sci. 2020,

10, 5872. Appl. Sci. 2021, 11, 1192.

https://doi.org/10.3390/app11031192

Received: 22 January 2021

Accepted: 25 January 2021

Published: 28 January 2021

Publisher's Note: MDPI stays neutral with regard to jurisdictional claims in published maps and institutional affiliations.

Copyright: (C) 2021 by the authors Licensee MDPI, Basel, Switzerland. This article is an open access article distributed under the terms and conditions of the Creative Commons Attribution (CC BY) license (https:// creativecommons.org/licenses/by/ $4.0 /)$.
The authors and journal retract the article, "Reconstructing the Dynamic Processes of the Taimali Landslide in Taiwan Using the Waveform Inversion Method" [1], cited above.

Following its publication, the authors contacted the editorial office regarding improper use of materials, without authorization.

Adhering to our complaints procedure, an investigation was conducted and the university was consulted. The decision was made that the article should be retracted.

This retraction was approved by the Editor-in-Chief of the journal. The authors agreed to this retraction.

\section{Reference}

1. Lin, G.-W.; Hung, C. Reconstructing the Dynamic Processes of the Taimali Landslide in Taiwan Using the Waveform Inversion Method. Appl. Sci. 2020, 10, 5872. [CrossRef] 